\title{
QUARTERLY TECHNICAL PROGRESS REPORT
}

Report Title:

Type of Report:

Reporting Period:

Contact:

Date of Report:

DOE Award Number:

Submitting Organization: Membrane Technology and Research, Inc. (MTR)

Subcontractors:

Other Partners:

Project Team: 1360 Willow Road, Suite 103

Menlo Park, CA 94025

Tel: (650) 328-2228

Fax: (650) 328-6580

www.mtrinc.com

Field Demonstration of a Membrane Process to Separate Nitrogen from Natural Gas: Tenth Quarterly Progress Report

Quarterly technical progress report

January 1, 2004 through March 31, 2004

Dr. Kaaeid Lokhandwala

Tel: (650) 328-2228 ext. 140

E-mail: kaaeid@mtrinc.com

April 30, 2004

None

ABB Lummus Global

Project Officer: Anthony Zammerilli

Contract Specialist: Keith L. Carrington 


\title{
Disclaimer
}

This report was prepared as an account of work sponsored by an agency of the United States Government. Neither the United States Government nor any agency thereof, nor any of their employees, makes any warranty, express or implied, or assumes any legal liability or responsibility for the accuracy, completeness, or usefulness of any information, apparatus, product, or process disclosed, or represents that its use would not infringe privately owned rights. Reference herein to any specific commercial product, process, or service by trade name, trademark, manufacturer, or otherwise does not necessarily constitute or imply its endorsement, recommendation, or favoring by the United States Government or any agency thereof. The views and opinions of authors expressed herein do not necessarily state or reflect those of the United States Government or any agency thereof.

\begin{abstract}
The original proposal described the construction and operation of a 1-MMscfd treatment system to be operated at a Butcher Energy gas field in Ohio. The gas produced at this field contained 17\% nitrogen. During pre-commissioning of the project, a series of well tests showed that the amount of gas in the field was significantly smaller than expected and that the nitrogen content of the wells was very high (25 to 30\%). After evaluating the revised cost of the project, Butcher Energy decided that the plant would not be economical and withdrew from the project. Since that time, Membrane Technology and Research, Inc. (MTR) has signed a marketing and sales partnership with ABB Lummus Global, a large multinational corporation. MTR will be working with the company's Randall Gas Technologies group, a supplier of equipment and processing technology to the natural gas industry.

Randall's engineering group has found a new site for the project at a North Texas Exploration (NTE) gas processing plant. The plant produces about 1 MMscfd of gas containing $24 \%$ nitrogen. The membrane unit will bring this gas to $4 \%$ nitrogen for delivery to the pipeline. The system has been installed in the field and initial startup activities have been completed. The system has not yet produced the flow rate required for continuous stable operation. NTE, the company hosting this test site/pilot plant, will drill additional wells to increase the inlet flow rate. The system is expected to be in full continuous operation by May 2004.
\end{abstract}

\section{Table of Contents}

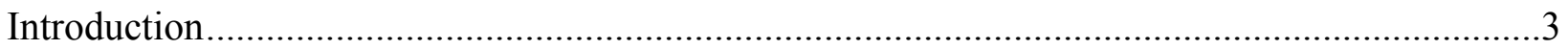

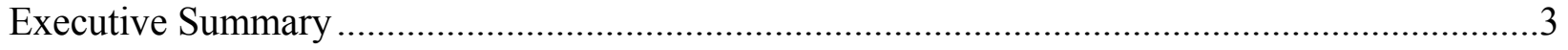

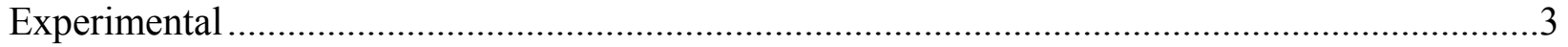

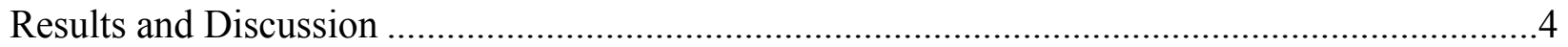

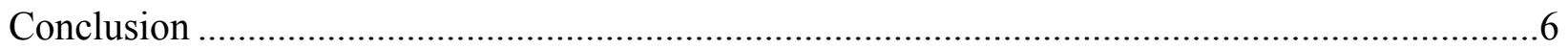

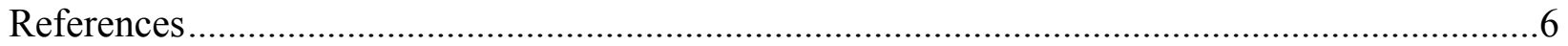




\section{Introduction}

The natural gas specification for inert gases is less than 4\%. On this basis, about $17 \%$ of known U.S. reserves of gas are subquality due to high nitrogen content. Some of this gas can be brought to pipeline specifications by dilution with gas of low nitrogen content; some is treated by cryogenic condensation and fractionation. Nonetheless, about 1.0 trillion scf of known reserves are currently shut in.

This project covers the first demonstration of a new membrane technology to treat this otherwise unusable gas. The objective of this project is to develop a membrane process to separate nitrogen from high nitrogen natural gas. To demonstrate the process, a proof-of-concept plant is being built at a North Texas Exploration (NTE) gas field in Texas/Oklahoma. Additional test sites are also being explored.

\section{Executive Summary}

Randall's engineering group has found a new site for the project at an NTE gas processing plant. The plant produces about 1 MMscfd of gas containing $24 \%$ nitrogen. The membrane unit will bring this gas to $4 \%$ nitrogen for delivery to the pipeline. The system has been installed in the field and initial startup activities have been completed. The inlet gas volume is lower than expected - and too low for continuous stable operation. NTE, the host company, will drill additional wells to increase the inlet flow rate. The system is expected to be in full continuous operation by May 2004.

\section{Experimental}

The membrane system was installed in the field and initial startup activities have commenced. We are waiting for the system to stabilize before collecting data. 


\section{Results and Discussion}

As part of the agreement between NTE, ABB, and MTR, MTR and ABB will supply NTE with a fully fabricated skid-mounted membrane unit that includes 28 eight-inch membrane inserts housed in eight pressure vessels. The process flow diagram of the system is shown in Figure 1.

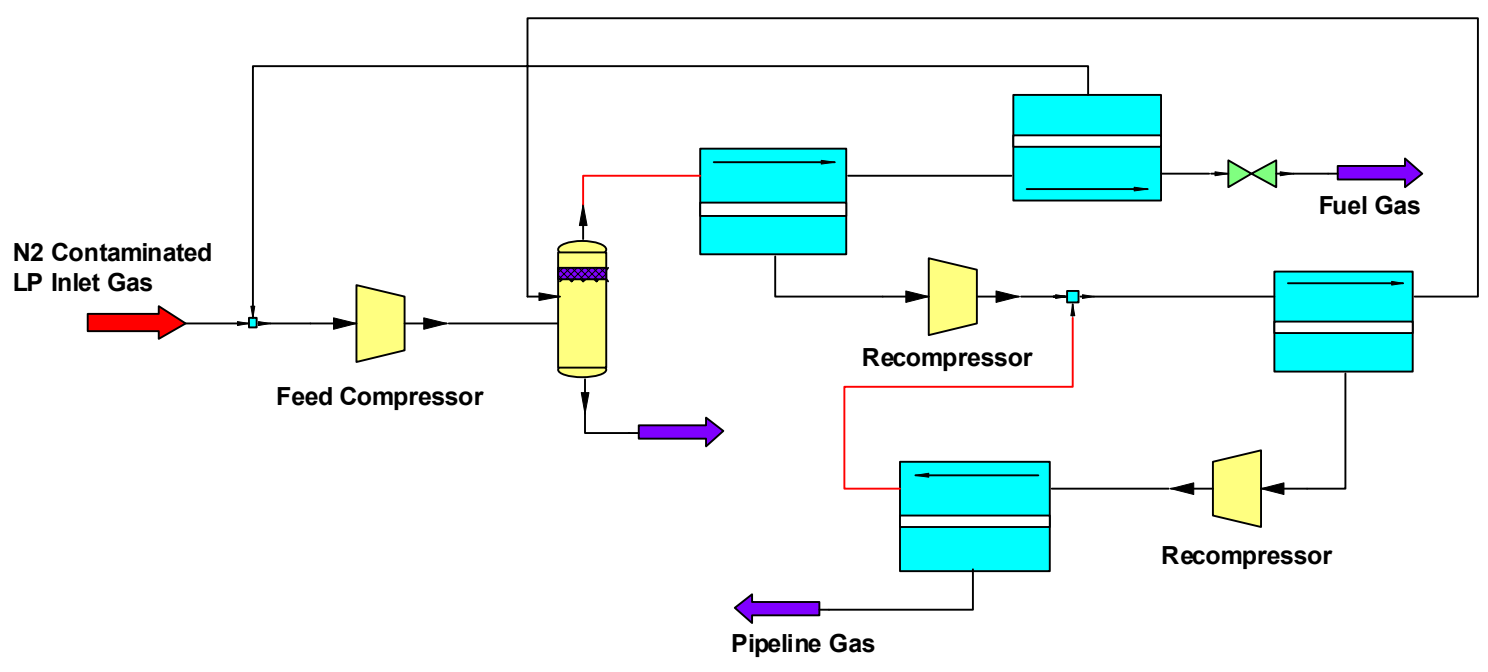

Figure 1. Process flow diagram for the NTE pilot plant system.

In this system, the low-pressure nitrogen contaminated gas is compressed to about $800 \mathrm{psia}$ and introduced into the membrane skid after passing through a filter coalescer. The gas passes through a set of membranes in two steps. In the first step (eight membrane inserts), partially enriched natural gas is produced as a permeate gas, compressed, and routed to a second stage for further purification. The non-permeate from the first step enters the second step (eight membrane inserts), where additional methane is recovered. This permeate stream is routed to the inlet compression. The nonpermeate from the second step is routed to fuel for the compression.

The partially purified gas from the first step is further purified in two more stages of membrane, the first containing eight membrane inserts and the second containing four membrane inserts. The final product is pipeline-quality natural gas.

During this reporting period, fabrication of the membrane skid was completed. A photograph of this skid in the fabrication shop is shown in Figure 2. A photograph of the system being installed in the field is shown in Figure 3. 


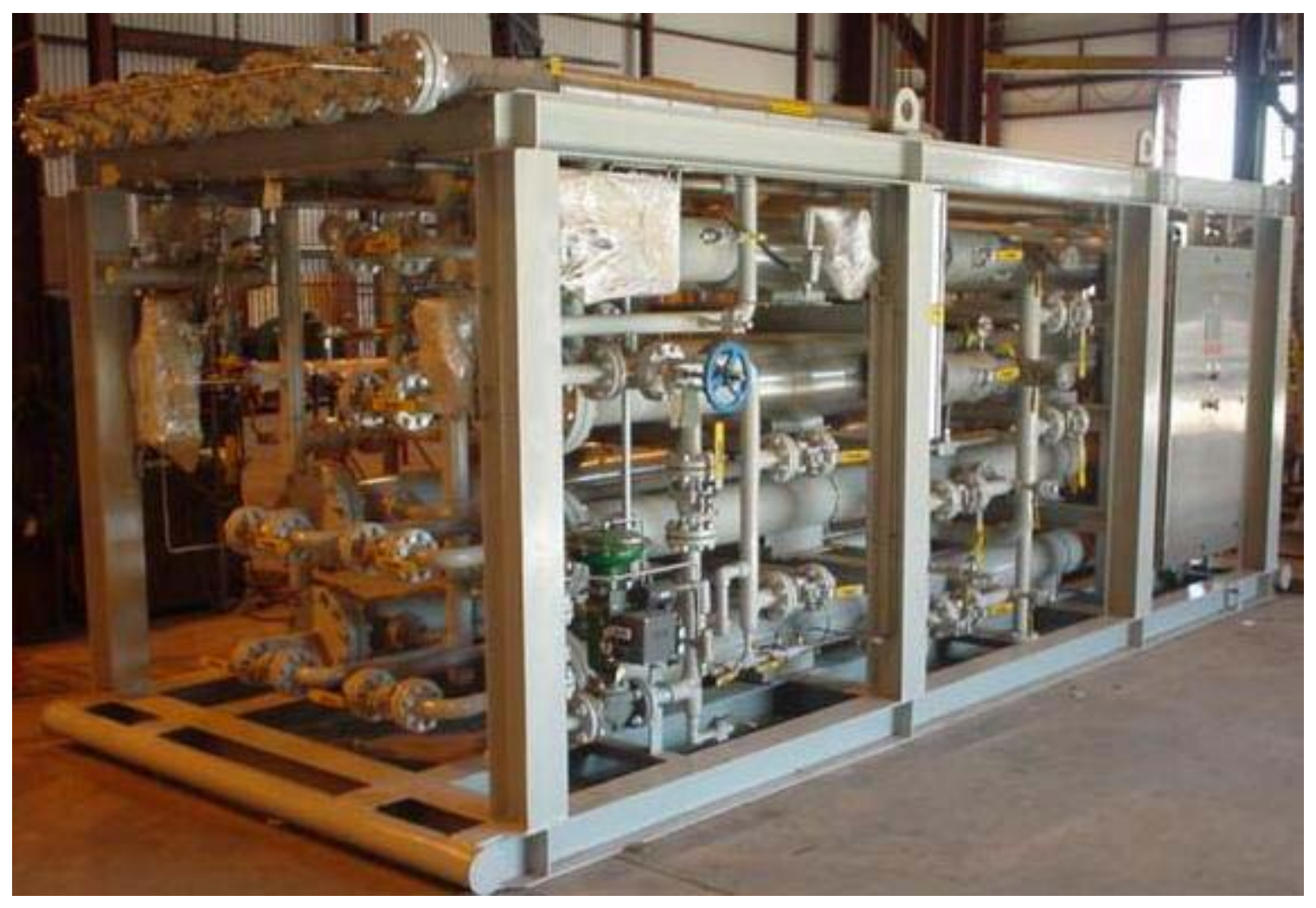

Figure 2. Photograph of the membrane skid for the NTE pilot test. 


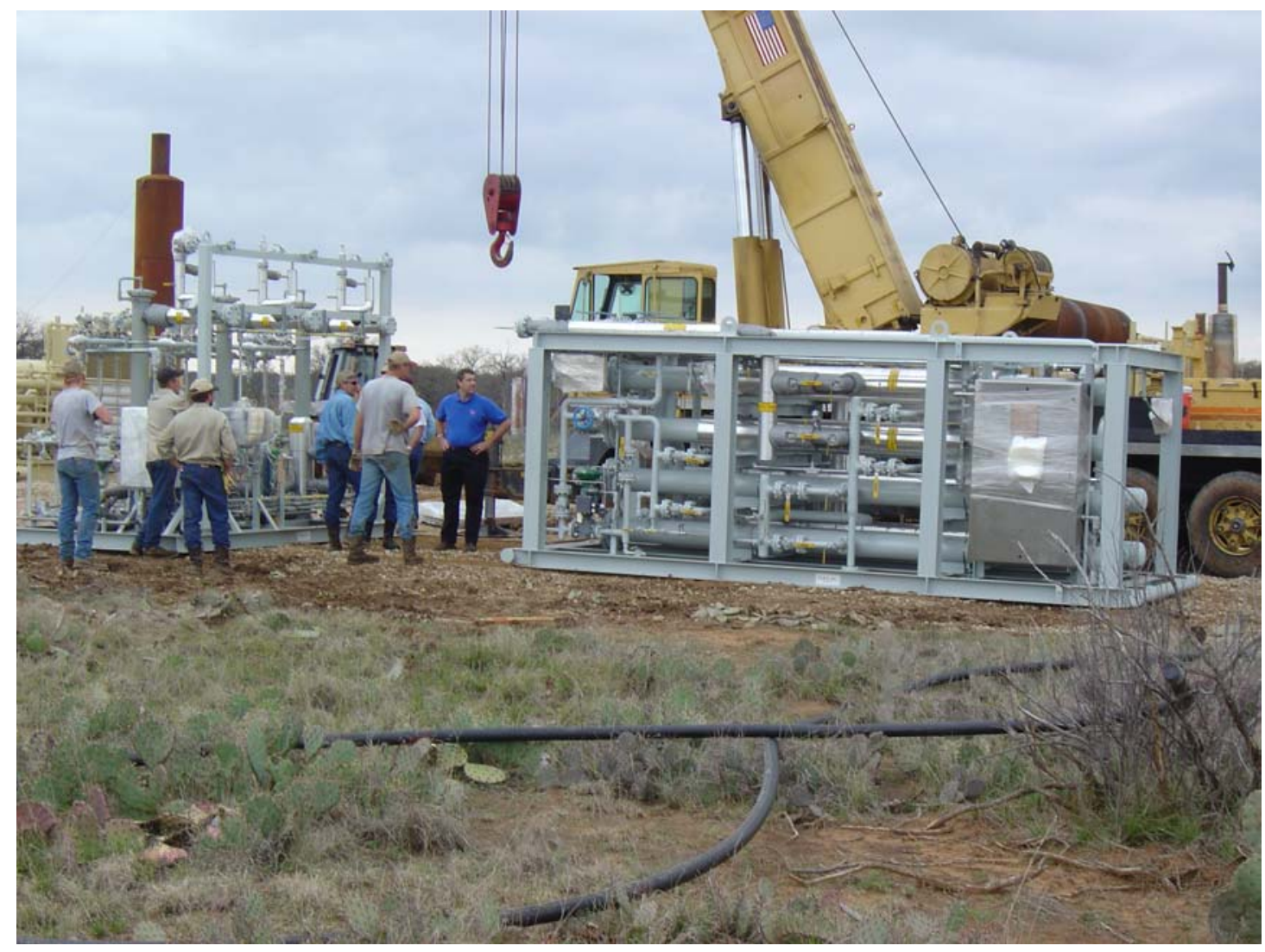

Figure 3. Membrane system being installed at Green Ranch, Texas.

MTR is negotiating to place a smaller existing system in Kentucky as a second field test/ semicommercial unit. The company involved in this second test is Twin Bottoms, LLC. The company has an existing production-ready operation that has been recently shut-in due to high nitrogen content. The MTR system will reduce the nitrogen content in the gas produced at this site from 5.5 to less then $4 \mathrm{~mol} \%$. MTR will provide the test system and support; the customer is willing to contribute upto $\$ 15,000$ as a cost share to support the test and demonstration activities. This system is currently being readied at MTR for delivery to the site in early June 2004.

\section{Conclusions}

The system has been installed in the field and initial startup activities have been completed. The inlet gas volume is lower than expected - and too low for continuous stable operation. NTE, the company hosting this test site/pilot plant, will drill additional wells to increase inlet flow rate. The system is expected to be in full continuous operation by May 2004.

\section{References}

None cited. 